\title{
Functional and Pathological Influence of Hypothermia on Spike Activity of Cortical Neurons
}

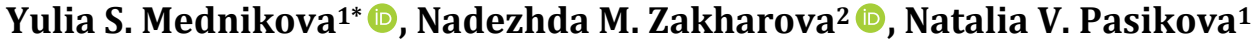 \\ ${ }^{1}$ Institute of Higher Nervous Activity and Neurophysiology of RAS, Moscow, Russia \\ ${ }^{2}$ ICB RAS, Federal Research Center "Pushchino Scientific Center for Biological Research of the Russian Academy of Sciences, \\ Pushchino, Russia \\ Email: ^mednikova.yu.s@ihna.ru
}

How to cite this paper: Mednikova, Yu.S., Zakharova, N.M. and Pasikova, N.V. (2021) Functional and Pathological Influence of Hypothermia on Spike Activity of Cortical Neurons. Journal of Behavioral and Brain Science, 11, 107-130.

https://doi.org/10.4236/jbbs.2021.115009

Received: April 2, 2021

Accepted: May 25, 2021

Published: May 28, 2021

Copyright $\odot 2021$ by author(s) and Scientific Research Publishing Inc. This work is licensed under the Creative Commons Attribution International License (CC BY 4.0).

http://creativecommons.org/licenses/by/4.0/

\begin{abstract}
In sensorimotor cortical slices of guinea pig using local iontophoretic application of glutamate to the soma and dendrites it was found that a decrease of temperature of incubating fluid from 34 to $21^{\circ} \mathrm{C}-22^{\circ} \mathrm{C}$ changes the somatic responses to the local injection of glutamate to the dendritic loci, while the responses to iontophoretic application of glutamate to the soma remain unchanged. Hypothermic changes in reactivity to dendritic stimulation start below $30^{\circ} \mathrm{C}$ and coincide with changes in the spontaneous activity of neurons, both in the direction of increasing and decreasing the frequency of firing in different nerve cells. On hypothermic decrease of spontaneous activity, the latencies of evoked dendritic responses on the soma became more longer, while on hypothermic increase of firing level, somatic spike responses to iontophoretic application of glutamate to dendritic loci appeared with shorter latencies. Hypothermic changes in the physiological parameters of neurons were accompanied by a drop in spike amplitude at the same temperature and with its further decrease. At the same time, there was a decrease of spike reaction to iontophoretic application of acetylcholine below $30^{\circ}$. It is proposed that the reason for hypothermic changes of neuronal activity is decreasing rate of $\mathrm{M}$-cholinergic process at $27^{\circ} \mathrm{C}-29^{\circ} \mathrm{C}$ which leads to opening $\mathrm{K}^{+}$ channels of neuronal membranes and hence to attenuation of conductive function of dendrites and to imbalance of $\mathrm{K}^{+}$ion homeostasis. Peculiarities of hypothermic regulation of neuronal spike activity depend on individual functional properties of cortical neurons.
\end{abstract}

\section{Keywords}

Cortical Slices, Spike Activity, Acetylcholine, Glutamate, Hypothermia, 


\section{Introduction}

When applying hypothermia and hypoxia exert almost identical disorders in nerve tissues and that is why hypothermic and hypoxic changes in neuronal activity are often considered together [1] [2] [3]. During long periods of even slight and moderate hypothermia $\left(t=32^{\circ} \mathrm{C}-34^{\circ} \mathrm{C}\right.$ and $\left.28^{\circ} \mathrm{C}\right)$, as well as during hypoxic periods of any degree, the membrane permeability to ions, supporting the stability of nerve membrane potential, increases, resulting in a flow of $\mathrm{Na}^{+}$and $\mathrm{K}^{+}$in the direction of their thermodynamic gradients. The occurring decrease of membrane potential opens potential-dependent $\mathrm{Ca}^{2+}$ channels and leads to pathologic entry of $\mathrm{Ca}^{2+}$ into cytosol, activation of phospholipases and proteases, disintegration of neuronal membranes and necrotic death of the neurons [2] [3] [4]. Such a dramatic chain of events describes the hypoxia-related disorders quite well, because the first sign of hypoxic condition of the brain is a blockade of $\mathrm{Na}^{+}-\mathrm{K}^{+}$-ATPase activity caused by deficiency of energy supply [5]. But under hypothermic condition the reason for imbalance of ionic processes remains unclear: the activity of $\mathrm{Na}^{+}-\mathrm{K}^{+}$-ATPase even slightly increases with the fall of temperature [6]; membrane potential and spike amplitude in neurons of frogs living at low temperatures (which are mortal for the brains of homoeothermic animals) have the same values as in mammalian neurons [7], while the energetic demands of cold-blooded brain are significantly less [3] [8]. That is why neither temperature-dependence nor energetic limitations of $\mathrm{Na}^{+}-\mathrm{K}^{+}$-ATPase activity should be considered as the reasons for the imbalance of ionic homeostasis in the cases of hypothermia. Noting this contradiction, P. W. Hochachka had supposed that there should be an additional mechanism sensitive to hypothermia, coupling membrane functions and cellular metabolism, which had not been taken into account earlier [3]. The evidence for such a mechanism follows from the fact that a lot of hypothermic alterations of brain activity are linked to the same temperature point: below $28^{\circ} \mathrm{C}$ the mammals lose consciousness [9] [10], below $28^{\circ} \mathrm{C}$ inflation of cortical EEG occurs [11], below $27^{\circ} \mathrm{C}-29^{\circ} \mathrm{C}$ the frequency of spontaneous neuronal activity decreases together with a sharp temperature decline of the activation spike reaction to acetylcholine [12] [13].

Muscarinic (M) cholinergic process is one of the main reactions of the brain. It is involved in maintaining consciousness [14], providing active perception [15], attention, memory and learning [16] [17]. Numerous functions of acetylcholine are associated with only M-cholinergic effect-regulation of membrane properties of neurons via metabolic process limiting $\mathrm{K}^{+}$permeability of cellular membranes, thus increasing their specific resistance [18] [19] [20]. Functional role of M-cholinergic process is related to regulation of conductive function of dendrites, providing the decrease of excitation decrement when propagating 
from dendrites to soma [21] and thus resulting in the increase of the level of spontaneous neuronal firing [22]. High sensitivity of M-cholinergic reaction to temperature [23] [13] and its dependence on the energy supply [24] were established.

Thus, the revealed fact of decreasing the rate of M-cholinergic reaction in hypothermia may be the reason of temperature-dependent ionic disbalance in the neurons, which had been proposed by P. W. Hochachka [3]. The main parameter regulated by hypothermia is the spontaneous activity of neurons [12]. The relationship of this parameter with the cholinergic reaction of the brain is traced by occasional change in the level of spontaneous firing [22]. The reason for the change in the spontaneous activity became clear when analyzing the process of dendrosomatic conduction of glutamatergic excitation, which turned out to be associated with a cholinergic effect that block $\mathrm{K}^{+}$channels on the neuronal membranes. Therefore, it was suggested that hypothermia can have a triple effect on the state of spike activity: ionic homeostasis can be disturbed [3], the rate of the M-cholinergic reaction can be changed [13] [23] together with the efficiency of dendrosomatic conduction [22]. Changes in all these parameters under conditions of hypothermia were supposed to be studied on the cortical slices with registration of spike activity. We used local delivery of mediators (glutamate and acetylcholine) to different points on the neuronal membrane in order to establish the factor of variability of dendrosomatic conductance and expression of the $\mathrm{M}$-cholinergic reaction. The variability of studied parameters was analyzed in different groups of neurons, differing in the rate of spontaneous activity. The pathological effect of hypothermia was analyzed by the change in the amplitude of neuronal spikes. It is quite possible that all hypothermic manifestations in the activity of nerve cells are united by a single cause.

\section{Methods}

\subsection{Slice Preparation and Incubation Conditions}

Animals were treated with observance of recommendation on ethics of work with animals offered by European Communities Council Direction (86/609 EEC) and experimental protocols approved by ethics committees of Institute of Higher Nervous Activity Russian Academy of Sciences. The experiments were carried out on slices of sensorimotor cortex of guinea pigs (weight $200-250 \mathrm{~g}$ ). After fast decapitation of the animals by guillotine and scull break-up, the brain surface was sprinkled by ice-cold aerated Ringer-Krebs solution. $500 \mu \mathrm{m}$ thick slices were prepared from longitudinal cortex block on VSL vibratome (World Precision Instruments, USA). Incubation chamber, where the slices were placed, was consisted of two cells (reserve and experimental) with independent flow of Ringer-Krebs solution. Incubation solution saturated by gas mixture $\left(95 \% \mathrm{O}_{2}\right.$ $+5 \% \mathrm{CO}_{2}$ ) consisted of the following components $(\mathrm{mM}): 124-\mathrm{NaCl} ; 5-\mathrm{KCl}$; $1.24-\mathrm{KH}_{2} \mathrm{PO}_{4} ; 1.3-\mathrm{MgSO}_{4} ; 2.4-\mathrm{CaCl}_{2} ; 26-\mathrm{NaHCO}_{3}$ and 10 -glucose (pH 7.4). Flow rate of incubating solution was $1.5-3 \mathrm{ml} / \mathrm{min}$. The slices were incubated at 
room temperature for half an hour after preparation. Then, the temperature was increased to $32^{\circ} \mathrm{C}-34^{\circ} \mathrm{C}$. The slices were incubated at this temperature for $1.5-2$ hours before the beginning of spike activity registration. The pre-heating of incubation medium was performed by U1 thermostat (VEB, Germany). For finer temperature regulation, a Peltier element-based thermostating device was used (NPO “Biopribor”, Russia). The temperature in experimental cell was controlled continuously by an electronic thermometer (NTC “NIKAS”, Russia).

\subsection{Electrodes and Recording Equipment}

Three-channel glass microelectrodes (diameter 7.4 - $8 \mu \mathrm{m}$ ) were used for extracellular registration of neuronal spike activity and for iontophoretic transmitter application. The channel for registration and channel for controlling iontophoretic current were filled with $3 \mathrm{M} \mathrm{NaCl}$. The third channel was filled with $1 \mathrm{M}$ sodium glutamate ( $\mathrm{pH}$ 7.5; Sigma Chemical Co., USA) or $2 \mathrm{M}$ acetylcholine chloride (pH 4.0; Sigma Chemical Co., USA). The channel for controlling iontophoretic current was often replaced by a second channel for transmitter phoresis, because the action of currents chosen for transmitter phoresis but being passed through current controlling channel did not evoke spike responses of recorded neurons. After amplification (DAM 80, World Precision Instruments, USA) and digitalization (E14-440, L-Card, Russia) the spike activity was inputted into computer (Intel (R) Core (TM) Duo) for storage, reproduction and processing of registered signals.

\subsection{Registration Area and Iontophoretic Current Parameters}

A three-barrel microelectrode containing channel for recording was moved along V layer of the cortex (1.2 - $1.6 \mathrm{~mm}$ from pial surface) in order to find spike activity of neurons and transmitter applications to the soma of registered nerve cells. After the detection of spike activity of a neuron, the independent micropipette, containing only phoretic channel, was placed at different points of presumable dendritic tree (Figure 1). Short-time bursts of spike activity registered by "somatic" electrode during glutamate application through "dendritic" electrode served as indicators of its location near dendritic surface [25]. The distance between somatic and dendritic micropipettes was measured by an eyepiece provided with micrometric scale. Glutamate was applied to dendrites and soma by 60 - $80 \mathrm{nA}$ current (negative pole inside the electrode); acetylcholine was applied to any membrane locus by $70 \mathrm{nA}$ current (positive pole inside the electrode). The duration of iontophoretic current for glutamate application was from 1 to $4.5 \mathrm{~s}$, whereas for acetylcholine application it was always $4.5 \mathrm{~s}$. Throughout an intervals between iontophoretic ejections the retaining 3 - $5 \mathrm{nA}$ current of opposite direction was set in each of phoresis channel. Iontophoretic glutamate application to local dendritic points in the course of gradual withdrawal of micropipette from the point of maximal effect allowed to find out that the effective dose of glutamate near dendritic surface could be achieved at the distance not 


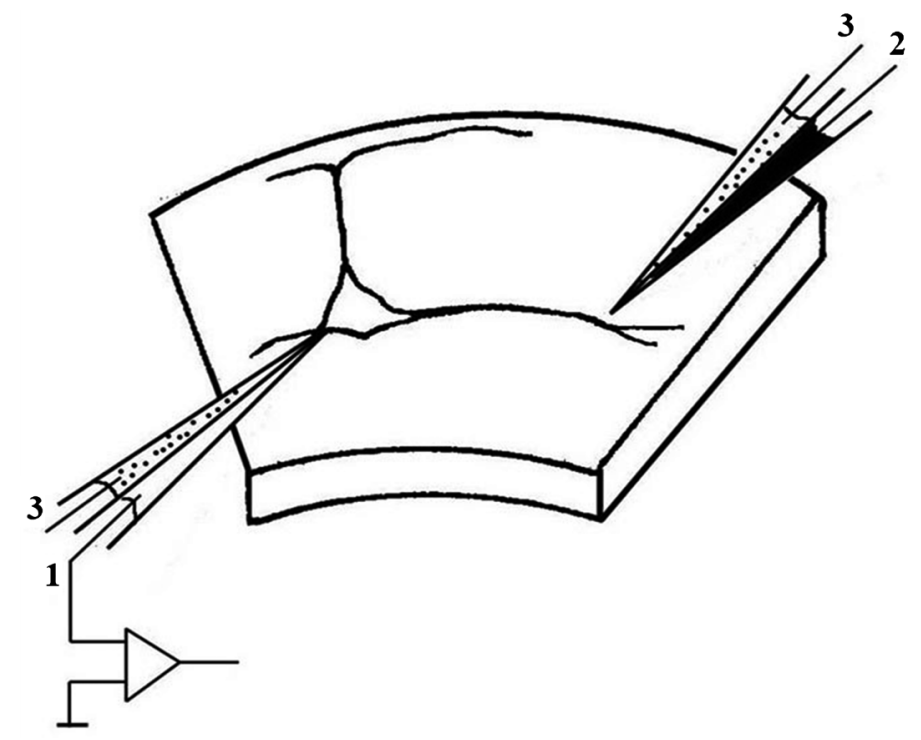

Figure 1. Scheme for recording spike activity and application of mediators to different loci of neuronal membrane. The spike activity was recorded from the neurons of layer $\mathrm{V}$ of guinea pig sensorimotor cortex in the soma region (1). The mediators were injected to soma region and dendritic loci: 2-channel for acetylcholine phoresis; 3-channel for glutamate phoresis.

exceeding $20 \mu \mathrm{m}$, which implies a high locality of iontophoretic action.

\subsection{Experimental Protocols}

Standard temperature, $32^{\circ} \mathrm{C}-34^{\circ} \mathrm{C}$, was maintained constantly in the reserve cell of incubating chamber, whereas in the experimental cell it was maintained during the procedure of searching for spike activity of the neurons and its control testing. Cooling the solution in the experimental cell to $21^{\circ} \mathrm{C}-24^{\circ} \mathrm{C}$ was performed with the rate of two degrees per minute. The rate of temperature restoration was the same. Thus, the whole cycle of hypothermic action took not longer than 10 minutes. During cooling, the neurons were always tested by a certain application manner: glutamate application to soma or dendrites every 12 $\mathrm{s}$ or acetylcholine application to soma every $24 \mathrm{~s}$. If registration conditions allowed, the neuronal activity was observed during an hour after the episode of hypothermia. Every hypothermic action was carried out usually on a fresh slice in order to avoid post-hypothermic events.

\subsection{Data Analysis}

The parameters of spike activity were analyzed by Power-Graph 3.3 computer program (PO "Power-Graph", Russia). An average level of spontaneous activity in 3-second interval before every iontophoretic application was calculated for pre-hypothermic, hypothermic and post-hypothermic periods. Spike amplitudes were also determined in these periods. Spike reactions of the neurons to transmitter application were estimated by the duration of latency period of the response and its intensity. Difference between maximal current average of spike 
frequency in the response and in preceding background activity served as estimates of the intensity of the reaction. The significance of the parameters' alterations was determined by non-parametric statistical methods [26].

\section{Results}

In the experiments on the layer $\mathrm{V}$ of sensorimotor cortex slices, the activity of 111 neurons was registered. The level of spontaneous activity varied from 0 to 25 impulses per second in different neurons. The distribution of the neurons in accordance with the level of spontaneous activity is presented on Figure 2. As can be seen, a significant majority of the neurons have no background activity. Presence of such neurons was detected by arising of spike activity in response to glutamate applied to the soma by short pulses of current. Among 111 nerve cells, $37.8 \%$ (42 neurons) had no spontaneous activity, 27 neurons (24.3\%) had spontaneous activity frequency up to 4 impulses per second, whereas high-frequency neurons (8 - 25 impulses per second) comprised $18.9 \%$ of the population (Figure 2).

The results of previous experiments [13] [22] and data obtained by other authors [27] gave evidence that alteration degree of spontaneous activity of the neurons significantly depends on their initial firing level. That's why the analysis of spontaneous activity frequency under short-time hypothermia was performed separately for the neurons divided in groups depending on the background activity level. Group I consists of neurons without background activity; group II included neurons with activity below 4 impulses per second; group III consists of neurons with activity from 4 to 8 impulses per second; group IV consists of

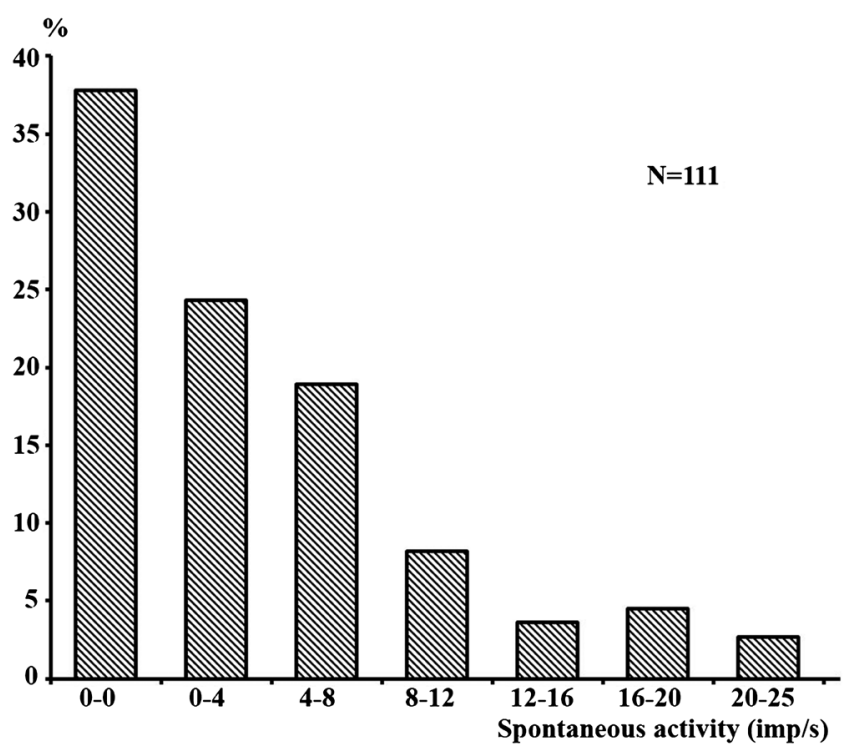

Figure 2. Distribution of neurons of the sensorimotor cortex according to the frequency of spontaneous activity. The abscissa shows the frequency of spontaneous activity (imp/s); The ordinate axis is the percentage of neurons that have a given level of spontaneous firing. At the top right is the number of registered neurons in the sensorimotor cortex. 
high-frequency neurons (from 8 to 25 impulses per second)

Overall, 35 neurons were registered during hypothermia procedure. Figure 3 shows most typical cases of changing spontaneous activity level in the neurons of
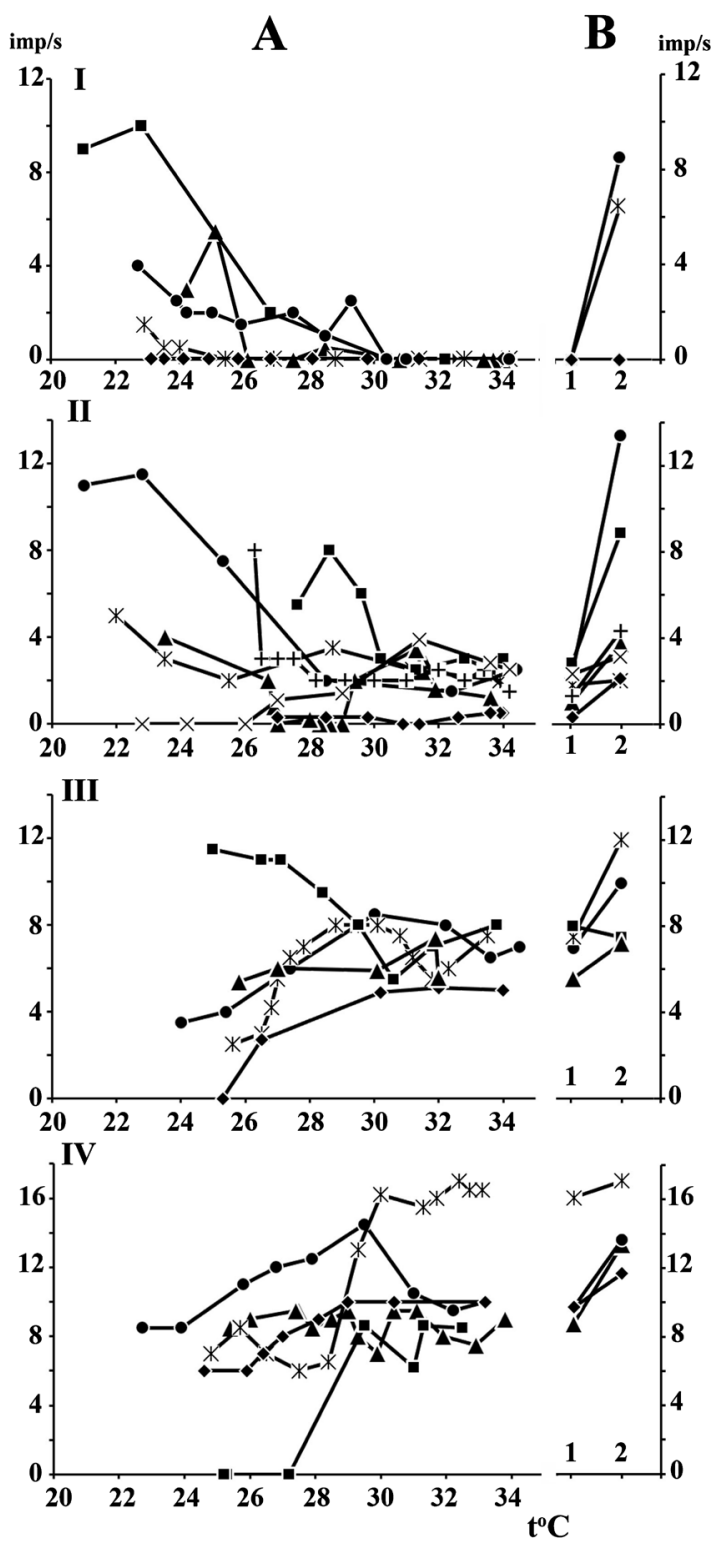

Figure 3. Frequency of spontaneous activity of sensorimotor cortex neurons in the course of decreasing temperature from $34^{\circ} \mathrm{C}$ to $21^{\circ} \mathrm{C}$ and after restoration of the initial temperature values. Each graph illustrates the dynamics of single neuron spontaneous activity frequency during cooling from $32^{\circ} \mathrm{C}-34^{\circ} \mathrm{C}$ to $21^{\circ} \mathrm{C}-22^{\circ} \mathrm{C}(\mathrm{A})$ and after restoration of the initial temperature (B). I, II, III, IV-four groups of nerve cells with different levels of spontaneous activity before cooling: I-neurons without spontaneous activity $(0 \mathrm{imp} / \mathrm{s})$; II-neurons with spontaneous activity frequency up to $4 \mathrm{imp} / \mathrm{s}$; III-neurons with spontaneous activity frequency from 4 to $8 \mathrm{imp} / \mathrm{s}$; IV-neurons with spontaneous activity frequency above $8 \mathrm{imp} / \mathrm{s}$. A: abscissa-temperature, ordinate-spontaneous activity frequency, (imp/s). B: horizontal axis - 1 and 2 , - the same temperature value $\left(32^{\circ} \mathrm{C}-34^{\circ} \mathrm{C}\right)$ before (1) and after (2) exposure to hypothermia; vertical axis - spontaneous activity frequency, (imp/s). 
all four groups during decrease of incubation liquid temperature in the experimental cell from $32^{\circ} \mathrm{C}-34^{\circ} \mathrm{C}$ to $21^{\circ} \mathrm{C}-22^{\circ} \mathrm{C}$ (Figure $3(\mathrm{~A})$ ) and further restoration of the temperature to the initial values (Figure 3(B)).

The specific feature for neurons of all four groups was the lack of significant difference in spontaneous activity level at $30^{\circ} \mathrm{C}$ compared to $34^{\circ} \mathrm{C}$ (Wilcoxon matched pairs signed rank test, $\alpha>>5 \%)$. Systematic changes of neuronal activity frequency began to appear by cooling incubation medium below $30^{\circ} \mathrm{C}$, having different rate of firing change in different neurons and as it is quite interesting, these changes may be either increase or decrease of spike activity in different neurons. The neurons with the same level of spontaneous activity under cooling and at $t=32^{\circ} \mathrm{C}-34^{\circ} \mathrm{C}$ were also present. Despite all the diversity of observed alterations, their dependence from the initial spontaneous activity level before cooling can be seen. Spontaneously inactive neurons almost in all cases of temperature fall below $30^{\circ} \mathrm{C}$ displayed the increase of spontaneous activity frequency the more significant the deeper cooling (Figure 3(A)-I). Among the neurons with spontaneous activity up to 4 impulses per second, the increase of activity rate during cooling also prevailed, but the decrease of spontaneous activity could also be found in certain neurons (Figure 3(A)-II). In the group of neurons having the activity of 4-8 impulses per second, the majority of registered cells displayed the decrease of spontaneous activity below $30^{\circ} \mathrm{C}$, but one neuron showed growth of frequency (Figure 3(A)-III). Finally, high-frequency neurons showed only decrease of spontaneous activity under hypothermia (Figure 3(A)-IV). The neurons from groups III and IV showed significant decrease of spontaneous activity under cooling revealed at $t=26^{\circ} \mathrm{C}$ compared to the level at $30^{\circ} \mathrm{C}$ (Wilcoxon matched pairs signed rank test, $\alpha<1 \%$ ). The significant increase of activity rate under hypothermia in groups I and II was achieved at $\mathrm{t}=24^{\circ} \mathrm{C}$ compared to $30^{\circ} \mathrm{C}$ (Wilcoxon matched pairs signed rank test, $\alpha<1 \%$ ).

Restoration of initial temperature values $\left(32^{\circ} \mathrm{C}-34^{\circ} \mathrm{C}\right)$ after episodes of hypothermia lead to the increase of spike activity compared to the level before cooling in almost all neurons for any character of activity changes under cooling (Figure 3(B); Wilcoxon matched pairs signed rank test, $\alpha<0.1 \%$ ). Hyperactivity of low-frequency neurons (groups I and II) was characterized by an increase of frequency by $231.4 \% \pm 40 \%$ compared to the level before cooling, and for the neurons with activity above 4 impulses per second (groups III and IV) it was only by $34.9 \% \pm 5 \%$ of the initial level. The hypothermia-induced increase of spike activity was maintained during long time after restoration of initial temperature: in one third of the neurons recovery period lasted as long as the post-hypothermic time of observation (1 hour). Fast restoration of activity frequency was detected mainly just for high-frequency neurons from group IV, which displayed full restoration of activity in $10-20$ min after episodes of hypothermia.

Cooling-related alterations of spontaneous activity level in nerve cells were accompanied by decrease of spike amplitude observed in all neurons without 
dependence on the direction of change of neuronal activity level under hypothermia (Figure 4(A)). The decrease of spike amplitude during cooling incubation medium from $34^{\circ} \mathrm{C}$ to $30^{\circ} \mathrm{C}$ was very slight: $6.3 \pm 0.5 \mu \mathrm{V}$ in average (Wilcoxon matched pairs signed rank test, $\alpha<5 \%$ ). A dramatic drop of spike amplitude, by $34.5 \pm 4 \mu \mathrm{V}$ on average, occurred when temperature had fallen from $30^{\circ} \mathrm{C}$ to $26^{\circ} \mathrm{C}$ (Wilcoxon matched pairs signed rank test, $\alpha<0.1 \%$ ). Further cooling led to even more significant decrease of spike amplitude down to complete spike elimination in the noise of certain neurons (Figure 4(A)). Restoration of initial temperature in overwhelming majority of cases did not lead to total restoration of spike amplitude (Figure 4(B)). The decrease of spike amplitude compared to the value before cooling was $15.5 \%$ on average (Wilcoxon matched pairs signed rank test, $\alpha<0.1 \%$ ). Half of the neurons did not display full restoration of spike amplitude even in hour of observation after hypothermic episode. Only in the group of high-frequency neurons (group IV) the majority of nerve cells showed restoration of initial spike amplitude right after restoration of initial temperature of incubation medium (Figure 4(B)-IV).

Thus, the level of spontaneous activity and spike amplitude of the neurons undergo the most significant alterations in the temperature range $27^{\circ} \mathrm{C}-29^{\circ} \mathrm{C}$. As shown earlier, a dramatic decrease of activation response to acetylcholine applied iontophoretically to nerve cells takes place in the same temperature range [13]. The reaction to acetylcholine comprises slow increase in spike activity frequency and a long lasting period of activation (till $10 \mathrm{~s}$ and more) after termination of phoretic current (Figure 5(I)-1 and Figure 5(II)-1), which shows that its development results from muscarinic mechanism [19] [20]. Nine neurons tested by acetylcholine applications during hypothermic action showed no significant difference in spike rate increments over background activity in response to acetylcholine at $34^{\circ} \mathrm{C}$ and $30^{\circ} \mathrm{C}$ (Wilcoxon matched pairs signed rank test, $\alpha>>5 \%$ ). Meanwhile, at $t=26^{\circ} \mathrm{C}-27^{\circ} \mathrm{C}$ acetylcholine applications exerted either no increase of spike activity above background level (Figure 5(I)-2) or the increase of firing was much weaker and had a longer latency period (Figure 5(II)-2). The reaction to acetylcholine estimated by increment of spike rate over the background level was significantly lower for all 9 neurons at $\mathrm{t}=26^{\circ} \mathrm{C}$ than at $t=30^{\circ} \mathrm{C}$ (Wilcoxon matched pairs signed rank test, $\alpha<1 \%$ ). It is also clearly shown on Figure 5(II) that spontaneous activity of the neuron may disappeared simultaneously with the weakening of the reaction to acetylcholine at $27^{\circ} \mathrm{C}$ (Figure 5(II)-1-2), which indicates on common temperature dependence of cholinergic process and the process of regulating spontaneous activity.

Figure 6 graphically demonstrates the changes of spontaneous activity level and increment of firing value under acetylcholine action during the decrease of temperature from $30^{\circ} \mathrm{C}-31^{\circ} \mathrm{C}$ to $26^{\circ} \mathrm{C}-27^{\circ} \mathrm{C}$. The temperature-related differences are presented for 9 neurons in percentage to the level of spontaneous activity (Figure 6(A)) and the expression of response to acetylcholine (Figure 6(B)) at $t=30^{\circ} \mathrm{C}-31^{\circ} \mathrm{C}$. As it was shown on Figure 3, the level of spontaneous activity 
in different neurons was either decreasing (5 neurons), or increasing (4 neurons) at $26^{\circ} \mathrm{C}-27^{\circ} \mathrm{C}$ (Figure $6(\mathrm{~A})$ ). At the same time, the response to acetylcholine during cooling was decreasing for any character of spontaneous activity changes;

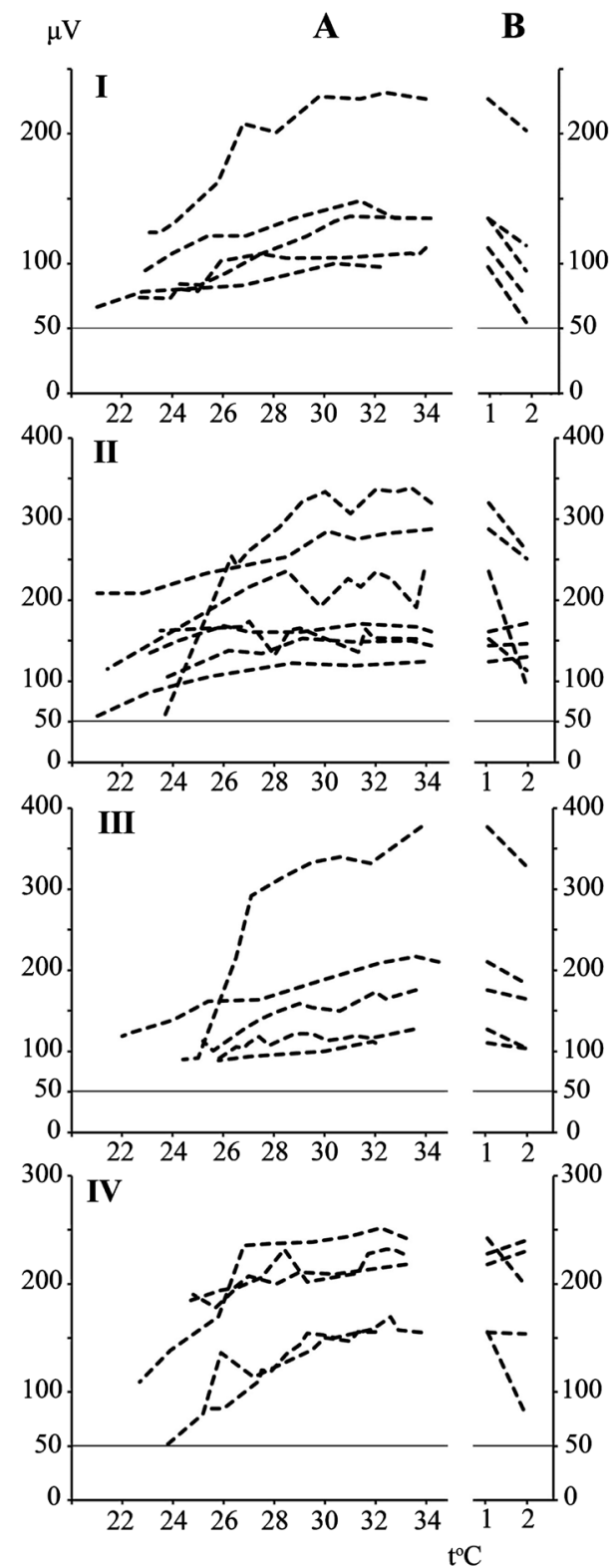

Figure 4. Spike amplitude of sensorimotor cortex neurons during decrease of temperature from $34^{\circ} \mathrm{C}$ to $21^{\circ} \mathrm{C}$ and further restoration of initial temperature values. Each graph illustrates the dynamics of single neuron spike amplitude changes during cooling from $32^{\circ} \mathrm{C}-34^{\circ} \mathrm{C}$ to $21^{\circ} \mathrm{C}-22^{\circ} \mathrm{C}$ (A) and during restoration of the initial temperature (B). Temperature-related changes of spike amplitude presented for the neurons which spontaneous activity is indicated on Figure 3(I-IV) - four groups of nerve cells with different levels of spontaneous activity before cooling (as shown on Figure 3). A: abscissa-temperature, ordinate-spike amplitude, $\mu \mathrm{V}$. B: horizontal axis- 1 and 2 , the same temperature value $\left(32^{\circ} \mathrm{C}-34^{\circ} \mathrm{C}\right)$ before (1) and after (2) exposure to hypothermia; vertical axis-spike amplitude, $\mu \mathrm{V}$. The line parallel to abscissa axis on each fragment designates noise level of the recording equipment. 


\section{Neuron 1}

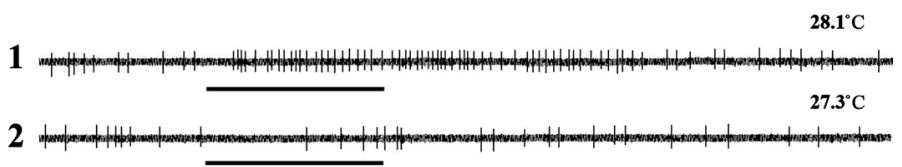

\section{Neuron 2}

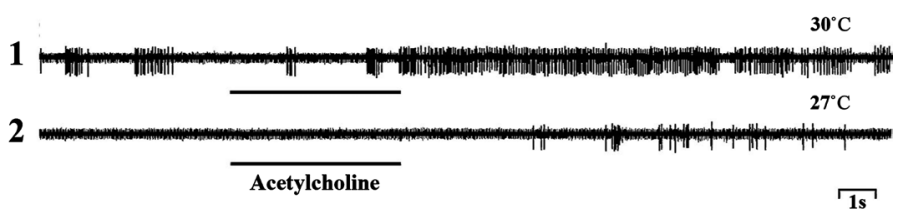

Figure 5. Responses of the sensorimotor cortex neurons to iontophoretic acetylcholine application during cooling of incubating medium below $30^{\circ} \mathrm{C}$. Represented two different neurons (I and II) of layer $\mathrm{V}$ of sensorimotor cortex. Acetylcholine was applied to the soma by $70 \mathrm{nA}$ current (positive pole inside the electrode) simultaneously with recording spike activity of the neurons. Neuronal spike activity was recorded at following temperatures: $\mathrm{I}-28.1^{\circ} \mathrm{C}(1) ; 27.3^{\circ} \mathrm{C}(2) ; \mathrm{II}-30^{\circ} \mathrm{C}$ (1) and $27^{\circ} \mathrm{C}$ (2). Duration of acetylcholine electrophoresis current is shown as a line under each record of neuronal activity.

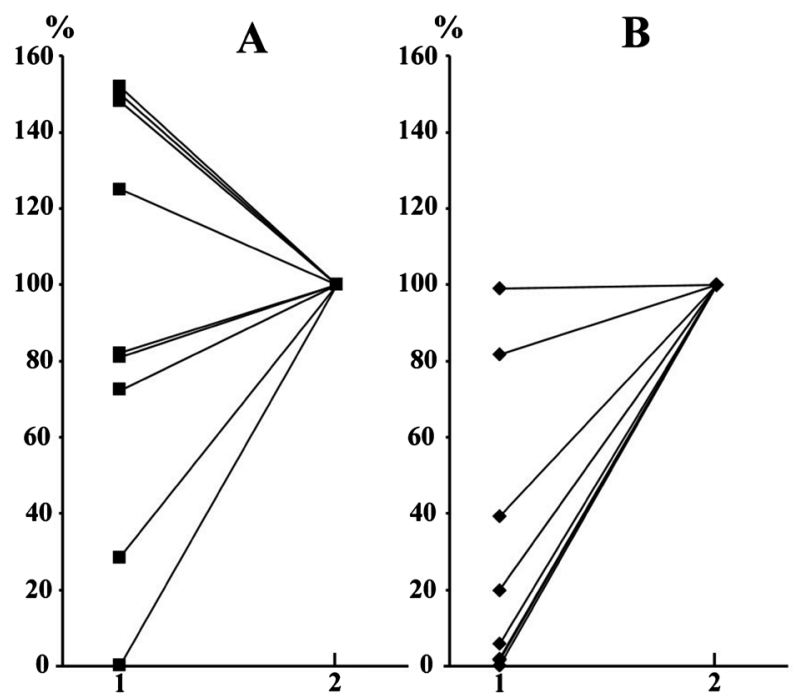

Figure 6. Changes in spontaneous activity level and level of the response to iontophoretic acetylcholine application during hypothermia. The plots schematically represent changes in activity of 9 sensorimotor cortical neurons tested by iontophoretic acetylcholine application during cooling the incubation medium. Electrophoretic acetylcholine current equals $70 \mathrm{nA}$ everywhere (positive pole inside the electrode). (A) Average level of spontaneous activity for each neuron. Horizontal axis: temperature values: 1) $t=26^{\circ} \mathrm{C}-27^{\circ} \mathrm{C}$; 2) $t=$ $30^{\circ} \mathrm{C}-31^{\circ} \mathrm{C}$; vertical axis-spontaneous firing rate of each neuron as percentage of $30^{\circ} \mathrm{C}$ $31^{\circ} \mathrm{C}$ level taken as $100 \%$. (B) Level of response of each neuron to iontophoretic acetylcholine application as a difference between maximal average spike frequency in response periods and in preceding background activity. Horizontal axis: temperature values like on A; vertical axis: level of response of each neuron to acetylcholine as percentage of response level at $t=30^{\circ} \mathrm{C}-31^{\circ} \mathrm{C}$ taken as $100 \%$.

for 7 of 9 neurons, the decline of the reaction was more than 60\% (Figure 6(B)). Thus, the decrease of $\mathrm{M}$-cholinergic reaction in temperature range $27^{\circ} \mathrm{C}-29^{\circ} \mathrm{C}$ 
causes both increase and decrease of spontaneous activity frequency in different neurons. This means that temperature-dependent decrease of cholinergic reaction rate may act in two opposite directions on mechanisms regulating spontaneous activity level.

The presence of two mechanisms regulating the level of spontaneous activity can be revealed by comparison of spontaneous change of activity level under standard temperature, $32^{\circ} \mathrm{C}-34^{\circ} \mathrm{C}$, and under the same temperature before and after hypothermic action. The shift to higher activity level at standard temperature conditions did not lead to significant changes of spike amplitude in cortical neurons (Wilcoxon matched pairs signed rank test, $\alpha>>5 \%$ ). At the same time, rising hyperactivity in nerve cells, registered after short episodes of hypothermia (Figure 3(B)) almost ever was accompanied by decrease of spike amplitude (Figure 4(B); Wilcoxon matched pairs signed rank test, $\alpha<1 \%$ ) at the same temperature $32^{\circ} \mathrm{C}-34^{\circ} \mathrm{C}$ before and after cooling. For comparison, Figure 7 shows two cases of increase of spike activity in different neurons: during hypothermic increase of firing activity (Figure $7(\mathrm{~A})$ ) and spontaneous change of activity under standard temperature conditions (Figure 7(B)). In the first case the increase of firing rate, started at $30.1^{\circ} \mathrm{C}$ and more expressed at lower temperature, was accompanied by significant (Wilcoxon-Mann-Whitney

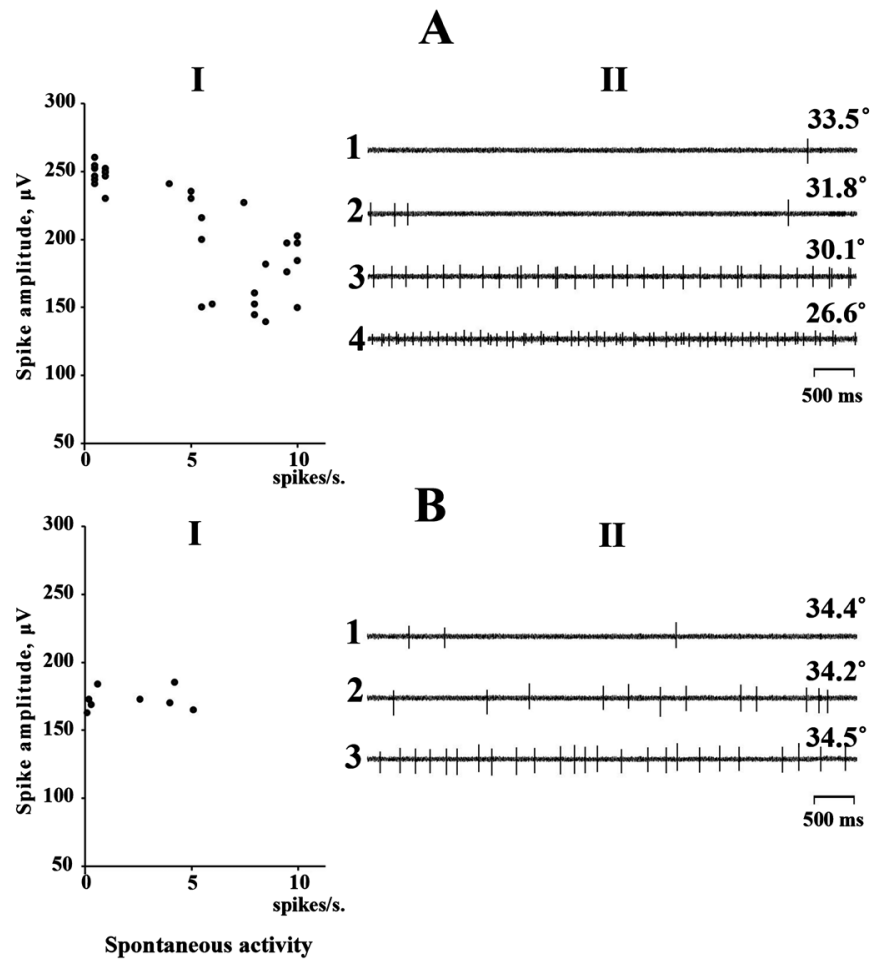

Figure 7. Hypothermia-induced and spontaneous increase of neuronal firing rate. The activity of two different neurons (A and B) is presented. (A) Increase of spike activity as a result of hypothermia. (B) Spontaneous increase of spike activity. I-Relations between firing rate (spikes/s) and spike amplitude $(\mu \mathrm{V})$. II-Records of spike activity: in A-1) before cooling $\left.\left(33.5^{\circ} \mathrm{C}\right), 2-4\right)$ in the course of cooling (from $31.8^{\circ} \mathrm{C}$ to $26.6^{\circ} \mathrm{C}$ ); in $\mathrm{B}$-each record made with $10 \mathrm{~min}$ intervals at temperature $34.2^{\circ} \mathrm{C}-34.5^{\circ} \mathrm{C}$. 
test, $\alpha<0.005$ ) fall of spike amplitude (Figure 7(A)-I and Figure 7(A)-II,1-4). In the second case the increase of discharge rate at nearly constant temperature had occurred without changes in spike amplitude (Figure 7(B)-I and Figure 7(B)-II,1-3).

Thus, the increase of activity frequency actually depends on two mechanisms, one of them being related to the drop of spike amplitude and another being not related to spike amplitude alterations. Both opportunities for increasing level of spontaneous activity, however, should depend on a single mechanism of its regulation. Earlier it was found that the neuronal spontaneous firing is as higher as shorter the latency period of somatic response to dendritic glutamate application [22] [28]. The same parameter was the most variable during changes of spontaneous activity level whatever the cause of these changes. Figure 8 shows the example of two cases of increasing duration of latency period of response to glutamate applied to dendritic point (100 $\mu \mathrm{m}$ from soma) of the same neuron, when spontaneous activity decreases to zero level.

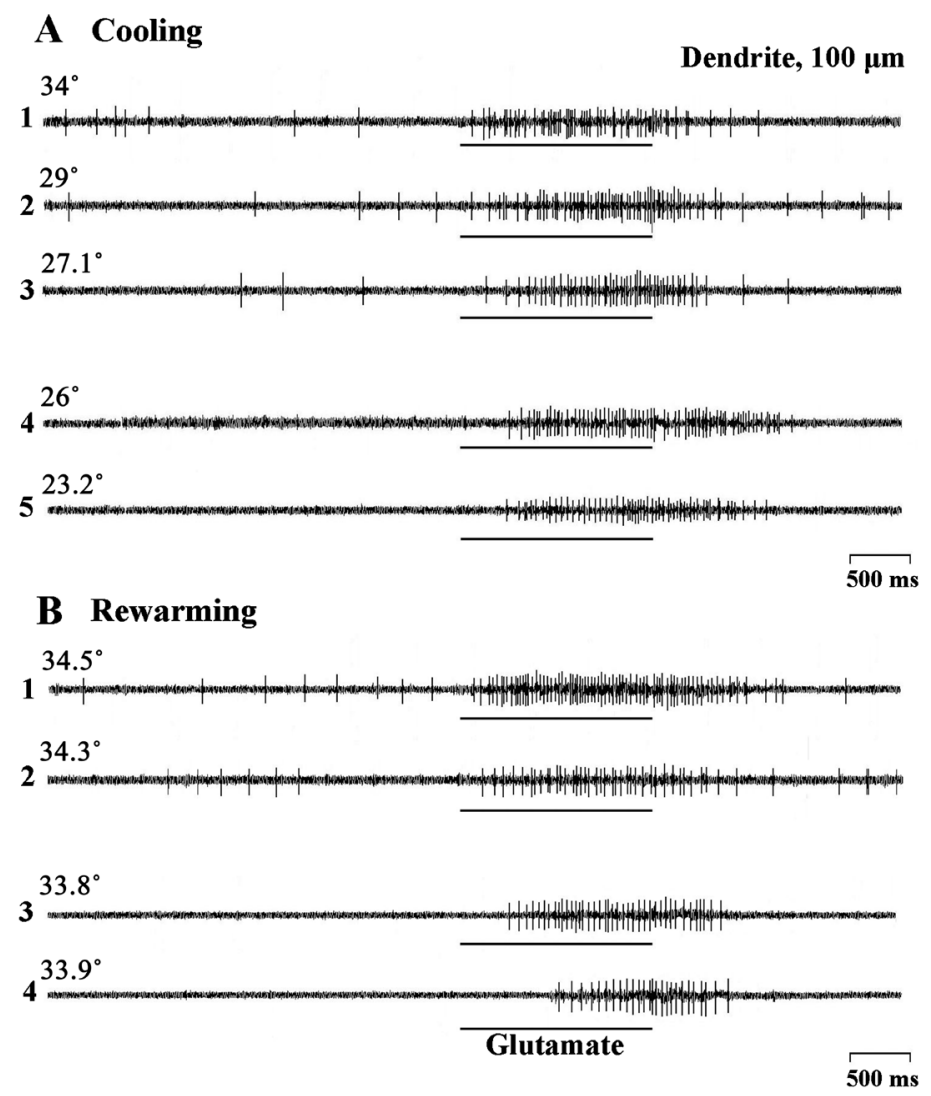

Figure 8. Hypothermia-induced and spontaneous decrease of spike activity of the sensorimotor cortical neuron during simultaneous recording of spike response to iontophoretic glutamate application to dendritic locus. Glutamate was applied to dendritic locus at $100 \mu \mathrm{m}$ from soma by $80 \mathrm{nA}$ current (negative pole inside the electrode). (A) activity of the neuron during cooling the incubation medium from $34^{\circ} \mathrm{C}$ to $23.2^{\circ} \mathrm{C}$ (1-5). (B) activity of the neuron in post-hypothermic period at different time moments after restoration of initial temperature: 1) $10 \mathrm{~min}$; 2) $15 \mathrm{~min}$; 3) 1 hour; 4) 1 hour $15 \mathrm{~min}$. Time of glutamate iontophoretic current is shown as a line under each record. 
In the first case (Figure 8(A)), the decrease of frequency took place under influence of cooling the incubation solution to $26^{\circ} \mathrm{C}$ and lower (Figure 8(A)-4-5) and it was accompanied by a slight decrease of spike amplitude. In the second case, the frequency dropped spontaneously while registering the activity at constant temperature (near $34^{\circ} \mathrm{C}$ ) 1 hour after hypothermic action (Figure 8(B)-3-4) and almost full restoration of spike activity changed during hypothermia (Figure 8(B)-1-2). In both cases, the decrease of spontaneous activity frequency occurred simultaneously with increase of latency period of the response to local glutamate application to dendritic point: from 150 to $400 \mathrm{~ms}$ in the first case and from $140 \mathrm{~ms}$ to 350 and $700 \mathrm{~ms}$ in the second one. Thus, both hypothermia-induced and spontaneous drops of frequency are related to weakening of dendritic impacts onto the neuronal soma.

Figure 9 illustrates similar changes under hypothermic influence observed after the decrease of temperature to $29^{\circ} \mathrm{C}$ and below. Spontaneous activity disappears at $29^{\circ} \mathrm{C}$ (Figure $9(\mathrm{~A})-4$ ) and increase of latency period of the response to glutamate application to dendritic locus occurs at the same temperature. The latency period of the reaction reaches the value of $2500 \mathrm{~ms}$ at $t=28^{\circ} \mathrm{C}$ (Figure 9(A)-6), whereas at $t=27^{\circ} \mathrm{C}$ a reverse process is beginning: the latency period of the response to local dendritic depolarization decreases to $400 \mathrm{~ms}$ (Figure 9(B)-1), followed by the restoration of spontaneous activity with higher frequency

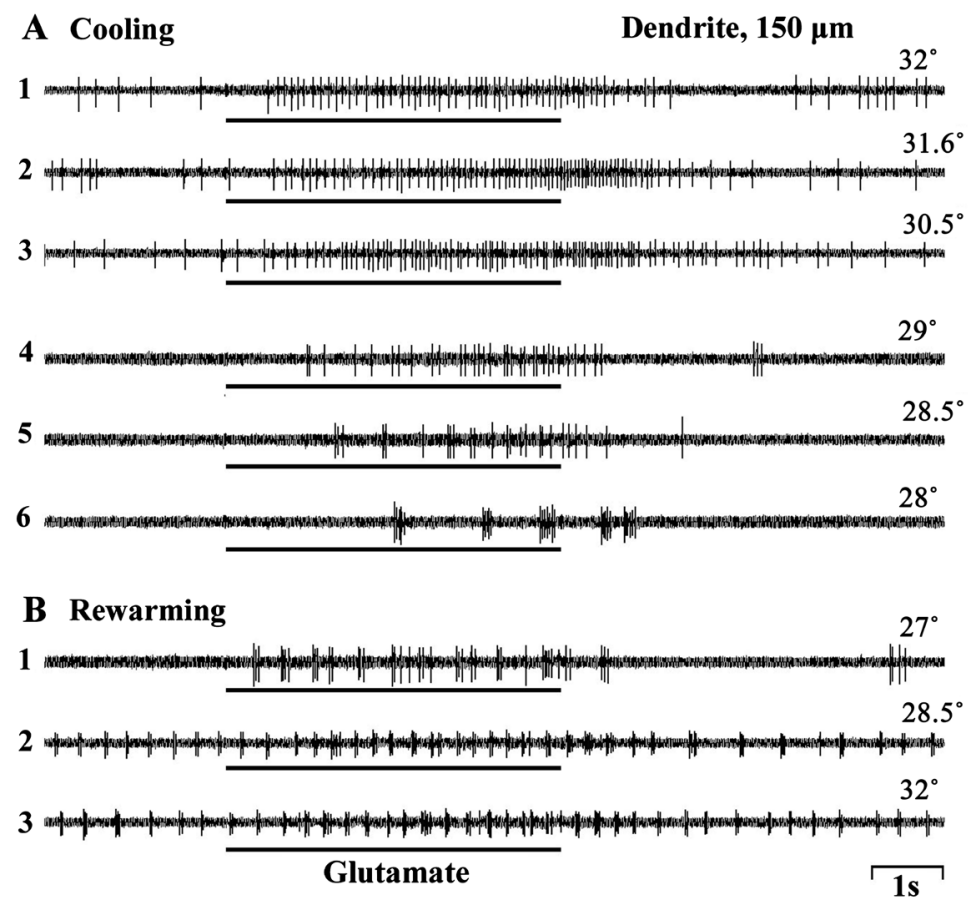

Figure 9. Responses of sensorimotor cortical neuron to iontophoretic glutamate application to dendritic locus during hypothermic decrease of spike frequency and its posthypothermic increase. Glutamate was applied to dendritic locus at $150 \mu \mathrm{m}$ from soma (A) when cooling the incubating medium from $32^{\circ} \mathrm{C}$ to $28^{\circ} \mathrm{C}(1-6)$ and (B) during temperature restoration (1-3). Iontophoretic current and duration of its action are the same as for Figure 8. 
at $t=28.5^{\circ} \mathrm{C}$. Restoration of spontaneous activity is accompanied by decrease of spike amplitude, increase of spike burst activity and masking the activation reaction to glutamate application by intensified spontaneous activity (Figure 9(B)-2-3).

Figure 10 shows a case of appearance of spontaneous activity under hypothermia after decrease of temperature below $26.9^{\circ} \mathrm{C}$ for the neuron, which was inactive at higher temperatures. The lifting of spontaneous activity is accompanied by decrease of spike response latency to local dendritic application of glutamate from $650 \mathrm{~ms}$ at $t=32.8^{\circ} \mathrm{C}-26.9^{\circ} \mathrm{C}$ (Figure $10(\mathrm{~A})-1-3$ ) to $350 \mathrm{~ms}$ at $t=$ $23^{\circ} \mathrm{C}$ (Figure 10(A)-5). These changes occur along with the decrease of spike amplitude. The following temperature restoration up to initial values demonstrates the hyperactivity phenomenon, i.e. maintenance of spontaneous activity in 10 minutes of incubation above $33^{\circ} \mathrm{C}$ with simultaneous short-latency reaction to local depolarization of a dendritic point (Figure 10(B)-1). After $15 \mathrm{mi}$ nutes of restoration period the spontaneous activity disappears and the spike response to dendritic glutamate application simultaneously with spike amplitude are restored (Figure 10(B)-2).

Stimulation of dendritic points (distance from soma ranging from 50 to 250 $\mu \mathrm{m})$ under hypothermic conditions was carried out on 20 neurons. As well as spontaneous activity level, the responses induced from dendrites also changed during cooling. Decrease of spontaneous activity level (6 neurons) was always accompanied by increase of latency periods or even disappearing of the response, independent on distance from the soma. Increase of spike frequency

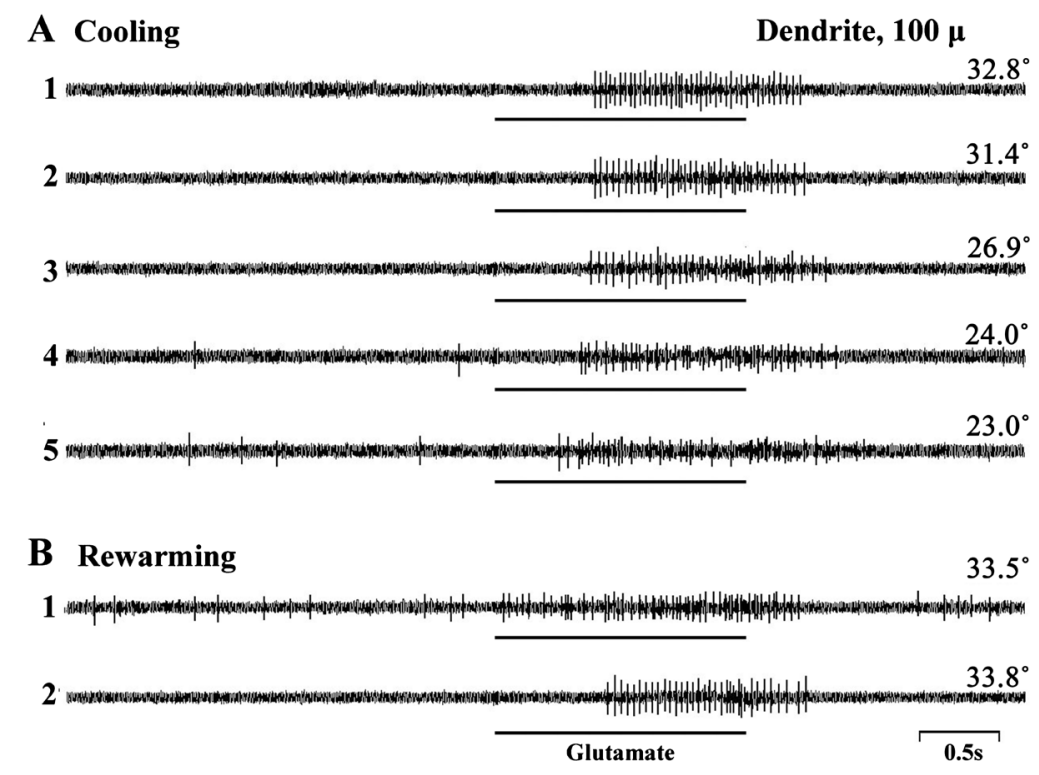

Figure 10. Increase of spontaneous activity of the neuron during hypothermia and responses to glutamate application to dendritic locus. Glutamate was applied to dendritic locus at $100 \mu \mathrm{m}$ from soma. (A) Records of neuronal activity during cooling the incubation medium from $32.8^{\circ} \mathrm{C}$ to $23^{\circ} \mathrm{C}$ (1-5); (B) Records of neuronal activity during restoration of incubation medium temperature: 1) $5 \mathrm{~min}$ after restoration, 2) $15 \mathrm{~min}$ after restoration. Iontophoretic current and duration of its action are the same as for Figure 8. 
when cooling or during post-hypothermic period took place either along with decrease of latency period of the response to dendritic stimulation (6 neurons), or (in the cases of markedly increase of spike frequency) along with masking of the response ( 3 neurons). If hypothermia did not cause changes in spontaneous activity, the changes in response expression to glutamate applied to dendrites also were not observed (5 neurons).

On the contrary, spike responses to glutamate applied to soma (6 neurons) were always stable in hypothermic conditions and did not change together with changing spontaneous activity. Figure 11 illustrates the stable spike reactions to glutamate injected to neuronal soma in wide temperature zone (from $33.6^{\circ} \mathrm{C}$ to $24.9^{\circ} \mathrm{C}$ ) while spontaneous activity is constant only from $33.6^{\circ} \mathrm{C}$ to $29^{\circ} \mathrm{C}(9$ $\mathrm{imp} / \mathrm{s}$-Figure $11(\mathrm{~A}))$, decreases below $29^{\circ} \mathrm{C}\left(7.4 \mathrm{imp} / \mathrm{s}\right.$ at $28.1^{\circ}$ and $4.6 \mathrm{imp} / \mathrm{s}$ at $24.9^{\circ}$-Figure $\left.11(\mathrm{~B})\right)$ and increases after restoration of the initial temperature from the hypothermic episode (12.6 imp/s-Figure 11(C)).

Thus, despite all the diversity of symptoms, the analysis of the effects of hypothermia on the activity of cortical neurons revealed the following:

1) A correlation between changing spontaneous activity caused by hypothermia and conductive efficiency of glutamatergic excitation along the dendrites was found.

2) In most of the cases, the decrease of spike amplitude had occurred when the temperature was decreased.

3) The revealed changes in the activity of cortical nerve cells occurred in temperature interval from $27^{\circ} \mathrm{C}$ to $29^{\circ} \mathrm{C}$, where excitatory spike reactions to acetylcholine sharply attenuates.

4) The neuronal spike reactions to glutamate, applied to soma are stable in the

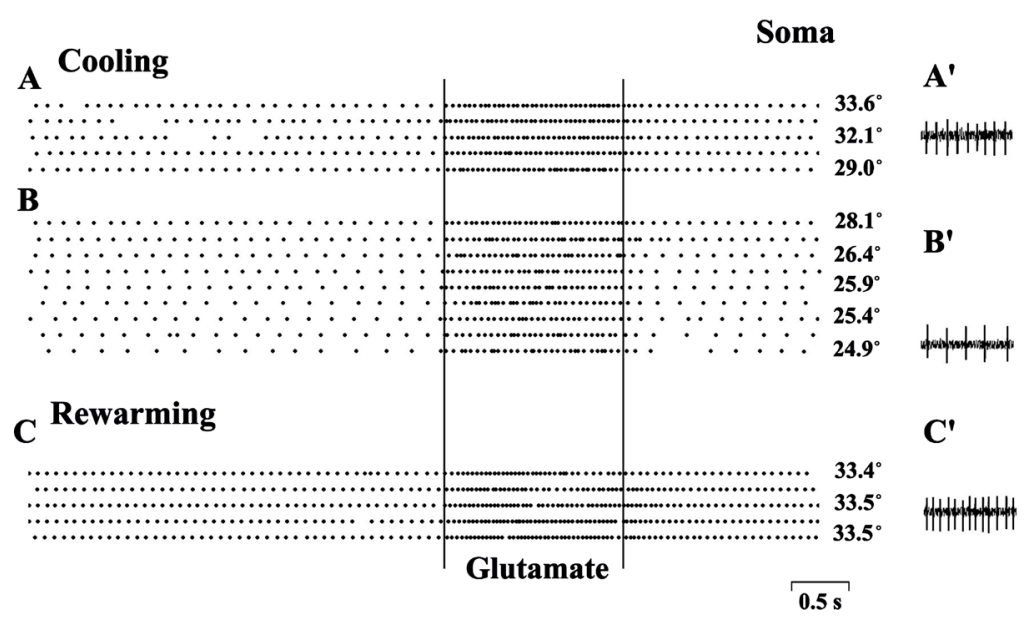

Figure 11. Changes of spontaneous activity of neuron during hypothermia and responses to somatic application of glutamate. Rasters spike density histograms during cooling the incubation medium from $33.6^{\circ} \mathrm{C}$ to $24.9^{\circ} \mathrm{C}$ (A) and (B) and after rewarming to initial temperature $(\mathrm{C})$. The time of glutamate injection to soma $(60 \mathrm{nA}$, negative pole inside the electrode) is restricted by vertical lines. (A') Spontaneous spike activity at temperature $33.6^{\circ} \mathrm{C}$; (B') Spontaneous spike activity at temperature $24.9^{\circ} \mathrm{C}$. (C') Spontaneous spike activity after restoration of initial temperature $\left(33.5^{\circ} \mathrm{C}\right)$. 
course of hypothermia.

\section{Discussion}

\subsection{The Main Reason of Hypothermic Effect in the Brain is the Temperature Related Attenuation of M-Cholinergic Reaction}

The obtained data give evidence that hypothermic action leads to serious disorders in the activity of cortical nerve cells. Small changes are occurring even in $34^{\circ} \mathrm{C}-30^{\circ} \mathrm{C}$ temperature range, comprising slight decrease of spike amplitudes of cortical neurons, but global problems begin to take place when cooling below $30^{\circ} \mathrm{C}$. As shown earlier [13] and confirmed by the current study (Figure 5 and Figure 6), below this point there is the first transition zone for M-cholinergic brain reaction, where $\left(27^{\circ} \mathrm{C}-29^{\circ} \mathrm{C}\right)$ the decrease of its rate occurs. M-cholinergic process blocks any types of $\mathrm{K}^{+}$channels on neuronal membranes [18] [19] [20] and sharp temperature related attenuation of this process provides additional growth of $\mathrm{K}^{+}$permeability and facilitates $\mathrm{K}^{+}$efflux from nerve cells in the direction of concentration gradient. Such ionic flow below $27^{\circ} \mathrm{C}$ is so significant in mammals that the capabilities of $\mathrm{Na}^{+}, \mathrm{K}^{+}-$ATPase to restore ionic homeostasis cannot fully compensate the disorder. The membrane potential begins to decrease, which leads to significant decrease of spike amplitude even under short hypothermia action (Figure 4). All other hypothermia-induced disorders are the consequences of these two processes, i.e. temperature limitation of M-cholinergic reaction rate and progressive $\mathrm{K}^{+}$ion accumulation in extracellular space.

\subsection{Mechanism of Formation and Regulation of Spontaneous Activity}

The most varying parameter during cooling is the frequency of spontaneous spike activity in nerve cells. The basic reason for formation of spontaneous activity is the constant flow of miniature dendritic glutamatergic EPSPs [29], which can have an amplitude of several tens $\mathrm{mV}$ at the origin points on dendrite loci [30], but are rapidly attenuated during motion towards the soma [29]. The conditions of more effective excitation moving along dendrites are determined by the geometry of neurons and specific resistance of their membranes [31]. That is why acetylcholine, blocking $\mathrm{K}^{+}$permeability of the neuronal membranes when interacting with M-cholinoreceptors [18] [19] [20], leads to both more effective excitation conduction along the dendrites [21] and increase of spontaneous activity level [22].

Limitation of $\mathrm{K}^{+}$permeability of the neuronal membranes could also be achieved via increase of extracellular $\mathrm{K}^{+}$concentration, which takes place at temperature below $27^{\circ} \mathrm{C}$, when the rate of $\mathrm{M}$-cholinergic process decreases. As a result, the specific resistance of cell membranes is increasing, which has been recorded as increase of input resistance below $27^{\circ} \mathrm{C}$ [32] [33] and has as consequence more effective conducting the flow of miniature excitatory postsynaptic potentials from dendrites to soma for its transformation into spike sequence. 
The proof for large increase of extracellular concentration of $\mathrm{K}^{+}$ions below $27^{\circ} \mathrm{C}$ is the inhibition of A-type $\mathrm{K}^{+}$current [34], the increase of spike width and slowing the rates of spike rise and fall recorded intracellularly [32] [33], as well as bursts formation in activity of some neurons after cooling and further temperature restoration (Figure 9). The adduced data point on a decrease of repolarization rate of neuronal membranes after depolarizing potential shifts, which is the consequence of increased $\mathrm{K}^{+}$concentration in extracellular medium below $27^{\circ} \mathrm{C}$. Therefore we conclude that two processes influence on spontaneous firing under hypothermia: from one side, the increase of membrane $\mathrm{K}^{+}$permeability via decrease of $\mathrm{M}$-cholinergic reaction rate at $27^{\circ} \mathrm{C}-29^{\circ} \mathrm{C}$, and from another side, decrease of $\mathrm{K}^{+}$permeability due to progressive growth of $\mathrm{K}^{+}$concentration in extracellular space. Prevailing of one or another process should depend on structural and membrane properties of the neurons, which would determine the dynamics of spontaneous spike activity changes of cortical neurons under cooling (Figure 3).

\subsection{Diversity of $\mathrm{K}^{+}$Membrane Conductance is Crucial for Peculiarities of Neuronal Activity during Hypothermia}

Density of $\mathrm{K}^{+}$channels on the membranes of mammalian cortical and hippocampal neurons is differently expressed on various nerve cells [35] [36]. $\mathrm{K}^{+}$conductance is increasing with age ever since 7-th day of life, and in mature cells becomes fully developed. Mature low-frequency hippocampal granule cells have input resistance lower than $200 \mathrm{M} \Omega$, suggesting that high density of $\mathrm{K}^{+}$channels is crucial for sparse firing (King et al., 2020). Due to this, one can imply that neurons having low [36] initial spontaneous activity level (up to 4 impulses per second, i. e. experimental groups I and II-Figure 3(A)) have a large average density of $\mathrm{K}^{+}$channels on the membranes. It may determine their low activity level as a result of a large decrement of EPSP amplitude when moving along the dendrites. For the same reason, hypothermic increasing $\mathrm{K}^{+}$permeability of the membranes below $27^{\circ} \mathrm{C}$ leads to rapid increase of $\mathrm{K}^{+}$concentration outside of these cells. That is why fast decrease of spike amplitude occurs, whereas spontaneous activity was increasing with further accumulation of $\mathrm{K}^{+}$ions in extracellular environment as a result of concentration-dependent increase of membrane resistance (Figure 3(A)-I-II; Figure 7(A)).

The opposite effect caused by hypothermia mainly in neurons with activity above 4 spikes per second (experimental groups III, IV-Figure 3(A)) is apparently linked to relatively low content of $\mathrm{K}^{+}$channels in their membranes. As a result, under $27^{\circ} \mathrm{C}$ the prevailing influence on spontaneous activity level is connected with opening of $\mathrm{K}^{+}$channels, leading to drop of conductive function of the dendrites and decrease of activity rate (Figure 3(A)-III-IV). Increase of extracellular $\mathrm{K}^{+}$concentration under these conditions is slow, appearing as a small decrease of spike amplitude and a slight hyperactivity after temperature restoration. 


\subsection{Hypothermic Pathology Related to Evolutionary Development}

Efflux of $\mathrm{K}^{+}$ions from neurons beginning at $27^{\circ} \mathrm{C}$ does not end further and can lead to a significant decrease of membrane potential level under further cooling or just in a certain time course [32]. Together with the depolarization shift, the drop of spike amplitude takes place (Figure 4), which is confirmed by earlier investigations [12] [37] [38], and the destructive intracellular processes are triggered [3] [8]. But even a small stable depolarization for potential-dependent $\mathrm{K}^{+}$ channels is quite sufficient to open ever more [39], causing further increase of $\mathrm{K}^{+}$ efflux from the cell and further depolarization shift [6]. Thus a self-maintained pathological process appears, resulting in increased extracellular $\mathrm{K}^{+}$concentration maintained for a long time after restoration of initial brain temperature. Experimentally it was observed as a long period of increased posthypothermic spontaneous activity frequency and long period of the decrease of spike amplitude.

The lack of change in activation spike reactions during glutamate application to soma on cooling (Figure 11) supports the results of previous studies [12] and evidences that glutamate sensitivity is not changing under hypothermia. This fact allows us to draw a conclusion that whatever the reason of change of neuronal spontaneous activity would be, its drop is finally related to the decrement of glutamatergic EPSP amplitude moving along the dendrites. Figure 8 and Figure 9 show that the disappearing of spontaneous activity below $27^{\circ} \mathrm{C}-29^{\circ} \mathrm{C}$ is coupled to prolongation of latency periods of responses to iontophoretic glutamate application to dendritic loci (Figure 8(A)-4-5 and Figure 9(A)-4-6). This means that under hypothermia the stationary excitation flow passing along the dendrites is so strongly attenuated that it can hardly penetrate the soma for overcoming its shunting properties. The same event can happen spontaneously (Figure 8(B)-3-4), without altering temperature, but due to spontaneous limitation of acetylcholine efflux from cholinergic synapses in the cortex [40] in registered zone. During the decrease of spontaneous activity under stationary conditions the prolongation of latency period of the response to glutamatergic stimulation of the dendrite appears to be even more significant than under action of hypothermia (Figure 8(B)-4 and Figure 8(A)-5), because it is regulated only by attenuation of influence from cholinergic system and is not interfered by the increase of membrane resistance related to the increase of extracellular $\mathrm{K}^{+}$content. Thus, the dendrites should be considered as a special machinery for spontaneous activity formation, which is finely regulated via alteration of $\mathrm{K}^{+}$permeability of neuronal membranes. At the temperatures specific for homoeothermic animals in stationary conditions it occurs mainly due to the regulating effect of brain cholinergic system.

The scheme on the Figure 12 demonstrates the changes in the cholinergic reaction during hypothermia in the temperature range of $27^{\circ} \mathrm{C}-29^{\circ} \mathrm{C}$. Above this range $\mathrm{M}$-cholinergic reaction performs an adaptive function, blocking $\mathrm{K}^{+}$ 
channels of neuronal membranes and increasing their resistance (Figure 12-1 and Figure 12-2). An increase in membrane resistance promotes more efficient conduction of excitation from dendrites and creates an adaptive growth of spontaneous activity. Below $27^{\circ} \mathrm{C}$, the rate of the M-cholinergic reaction decreases, which leads to opening the $\mathrm{K}^{+}$channels and the gradual leakage of $\mathrm{K}^{+}$ ions from the cell (Figure 12-3). This process is opposite to that which take place in the adaptive zone of cholinergic action - membrane resistance and spontaneous activity are falling. In this case the adaptive function of acetylcholine weakens, but it is replaced by a passive process of reducing the $\mathrm{K}^{+}$transmembrane current due to concentration accumulation of $\mathrm{K}^{+}$ions on the outer side of the membrane (Figure 12-4). Membrane resistance increases and conduction of excitation from dendrites improves. The resulting passive growth of spontaneous activity is not adaptive. It occurs as a consequence of a growing impairment of ionic homeostasis and coincided with the fall of spike amplitude. This state, named delirium, with further equalization of the $\mathrm{K}^{+}$ions concentration on the both sides of the membranes can lead to cold death.

The described functional and pathological changes in the nervous system during hypothermia have another feature-they are characteristic only for warm-blooded neuronal content. The rate of $\mathrm{M}$-cholinergic reaction in temperature range $27^{\circ} \mathrm{C}-36^{\circ} \mathrm{C}$ is sharply increasing twice. The first temperature dependent shift at $27^{\circ} \mathrm{C}-29^{\circ} \mathrm{C}$ is a reason for hypothermic disorder of activity of the cortical neurons. The second temperature-dependent shift occurs at $34^{\circ} \mathrm{C}$ -

\section{Zone of adaptive cholinergic function}

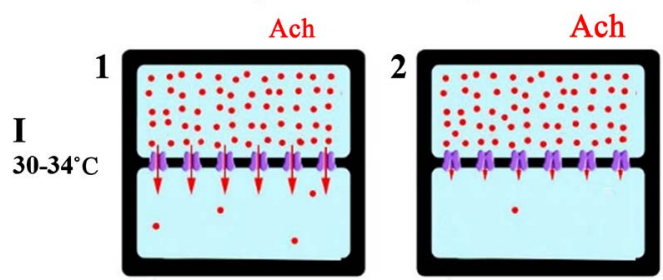

\section{Zone of attenuated cholinergic function}

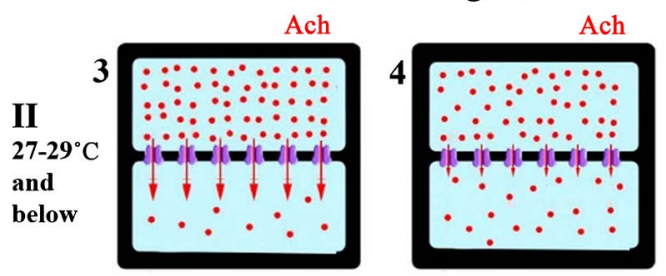

Figure 12. Scheme of hypothermic effect on the cholinergic reaction and $\mathrm{K}^{+}$transmembrane current. Each fragment of the figure $(1-4)$ depicts the neuronal inside (top) and outside environment which are separated by a membrane with built-in $\mathrm{K}^{+}$channels. The circles represent potassium ions, arrows indicate $\mathrm{K}^{+}$transmembrane current under different functional conditions. The rate of $\mathrm{M}$-cholinergic reaction (concentration-depended - I and temperature-depended - II) is indicated by different font sizes depicting the effect of acetylcholine (Ach). 1 and 2 - state of $\mathrm{K}^{+}$permeability with different release of acetylcholine (Ach) in zone I; 3 and 4 - different state of $\mathrm{K}^{+}$permeability during hypothermia (zone II) and accumulation of $\mathrm{K}^{+}$ions in the outer side of the membrane over time. 
$36^{\circ} \mathrm{C}$ and is characterized by significant increase of the rate of the process [13]. The high rate of cholinergic reaction regulating the permeability state of $\mathrm{K}^{+}$channels of neuronal membranes at brain temperatures normal for homoeothermic animals requires great energetic support. The energetic demands of this process can be fully provided only by perfecting of circulatory, respiratory, digestive and other organs, which makes the difference between the any of homoeothermic animals and their poikilothermic evolutionary precursors [8]. Thermodynamically almost impossible affords to regulate specific for homoeothermic animals low-ohm neuronal membranes lead to high dependence of their brain from energetic supply, the lack of which leads straight to hypoxic disorders [3] [5] [8] despite the additional existence of glial cells that contribute to efficient energy supply of neurons and maintain ionic constancy of the extracellular compound [41] [42]. The pathological alterations caused by hypoxia are absolutely identical to pathological processes occurring under hypothermia because the first sign of hypoxia is limitation of $\mathrm{Na}^{+}, \mathrm{K}^{+}$-ATPase activity followed by accumulation of $\mathrm{K}^{+}$ions in extracellular space [5]. That is why hypoxia and hypothermia are equally destructive for mammals, and the Nature leaves us only $1.5^{\circ} \mathrm{C}$ temperature interval for normal functional working of our perfect brain [8]. And what a high price had to be paid for this perfection.

\section{Conclusion}

The main reason of hypothermic disorders in functional activity of cortical neurons is temperature-dependent limitation of the rate of $\mathrm{M}$-cholinergic reaction of the brain, which is a regulator of membrane properties of nerve cells by closing $\mathrm{K}^{+}$channels. The decrease of this process rate below $27^{\circ} \mathrm{C}$ reduces the influence of excitation, permanent arising in dendrites, on the soma, resulting fall of spontaneous activity, and in the case of homoeothermic animals leads to neuronal homeostasis impairment and $\mathrm{K}^{+}$accumulation in extracellular space. This is the reason of spike amplitude attenuation and pathological rise of spontaneous firing in some cortical neurons under hypothermic conditions. Different functional properties of cortical neurons, providing the different efficiency of dendro-somatic propagation, determine the peculiarities of neuronal response to hypothermia. Spike reactions to glutamate applied to soma are stable in the course of hypothermia.

\section{Acknowledgements}

Research was supported by the Russian Academy of Sciences.

\section{Conflicts of Interest}

The authors declare no conflicts of interest regarding the publication of this paper.

\section{References}

[1] Alkan, T. and Korfali, E. (2000) Hypothermia in Neuronal Protection. Turkish Neu- 
rosurgery, 10, 1-13.

[2] Boutilier, R.G. (2001) Mechanisms of Cell Survival in Hypoxia and Hypothermia. Journal of Experimental Biology, 204, 3171-3181. https://doi.org/10.1242/jeb.204.18.3171

[3] Hochachka, P.W. (1986) Defense Strategies against Hypoxia and Hypothermia. Science, 231, 234-241. https://doi.org/10.1126/science.2417316

[4] Warren, D.E., Bickler, P.E., Clark, J.P., Gregersen, M., Brosnan, H., McCleroy, W. and Gabatto, P. (2012) Hypothermia and Rewarming Injury in Hippocampal Neurons Involve Intracellular $\mathrm{Ca}^{2+}$ and Glutamate Excitotoxicity. Neuroscience, 207, 316-325. https://doi.org/10.1016/j.neuroscience.2011.12.034

[5] Lipton, P. (1999) Ischemic Cell Death in Brain Neurons. Physiological Reviews, 79, 1431-1568. https://doi.org/10.1152/physrev.1999.79.4.1431

[6] Aslanidi, K.B., Aslanidi, G.V., Varchadze, D.M., Zinchenko, V.P. and Labas, Yu.A. (1997) Possible Participation of Ionic Stress in Cells' Cold Death. Biologicheskie Membrany, 14, 50-65. (In Russian)

[7] Eccles, J.C. (1957) The Physiology of Nerve Cells. J. Hopkins Press, Baltimore.

[8] Ivanov, K.P. (2004) Principles of Energetics in an Organism: Theoretical and Applied Aspects. Vol. 4. Energy Resources of Organism and Physiology of Survival. Nauka, St. Petersburg. (In Russian).

[9] Ivanov, K.P. (1996) Changes of Physiological Functions, Mechanisms of Their Restoration and Temperature Limitations of Life Under Hypothermia. Uspekhi Fiziologicheskikh Nauk, 27, 84-105. (In Russian)

[10] Prosser, C.L. (1973) Temperature. In: Prosser, C.L., Ed., Comparative Animal Physiology, WB Saunders Company, Philadelphia, London, Toronto, 362-428.

[11] Ignatev, D.A., Gordon, R.Ya., Vorobev, V.V. and Rogachevsky, V.V. (2005) Evolution of Electroencephalographic and Protein-Synthesizing Activities of the Neocortex and Hippocampus During Rewarming after Hypothermia in Hibernating (Ground Squirrel) and Nonhibernating (Rat) Animals. Biophysics, 50, 132-142.

[12] Mednikova, Y.S., Pasikova, N.V. and Kopytova, F.V. (2004) Effects of Temperature on the Spike Activity of cortical Neurons in Guinea Pigs. Neuroscience and Behavioral Physiology, 34, 459-465. https://doi.org/10.1023/B:NEAB.0000022630.53594.99

[13] Mednikova, Y.S., Pasikova, N.V., Isakova, A.V. and Kopytova, F.V. (2008) Cholinergic Process and Functional State of Cortical Neurons under Conditions of Artificial Incubation. Neurochemical Journal, 2, 115-119.

[14] Magoun, H.W. (1958) The Waking Brain. Charles Thomas Publisher, Springfield. https://doi.org/10.1037/11149-000

[15] Acquas, E., Wilson, C. and Fibiger, H.C. (1996) Conditioned and Unconditioned Stimuli Increase Frontal Cortical and Hippocampal Acetylcholine Release: Effects of Novelty, Habituation, and Fear. Journal of Neuroscience, 16, 3089-3096. https://doi.org/10.1523/JNEUROSCI.16-09-03089.1996

[16] Bentley, P., Driver, J. and Dolan, R.J. (2011) Cholinergic Modulation of Cognition: Insights from Human Pharmacological Functional Neuroimaging. Progress in Neurobiology, 94, 360-388. https://doi.org/10.1016/j.pneurobio.2011.06.002

[17] Hattori, R., Kuchibhotla, K.V., Froemke, R.C. and Komiyama, T. (2017) Functions and Dysfunctions of Neocortical Inhibitory Neuron Subtypes. Nature Neuroscience, 20, 1199-1208. https://doi.org/10.1038/nn.4619

[18] Brown, D.A., Abogadie, F.C., Allen, T.G.J., Buckley, N.J., Caulfield, M.P., Delmas, 
P., Haley, J.E., Lamas, J.A. and Selyanko, A.A. (1997) Muscarinic Mechanisms in Nerve Cells. Life Sciences, 60, 1137-1144. https://doi.org/10.1016/S0024-3205(97)00058-1

[19] Krnjević, K., Pumain, R. and Renaud, L. (1971) The Mechanism of Excitation by Acetylcholine in the Cerebral Cortex. Journal of Physiology $(L), 215,247-268$. https://doi.org/10.1113/jphysiol.1971.sp009467

[20] McCormick, D.A. and Prince, D.A. (1986) Mechanisms of Action of Acetylcholine in the Guinea-Pig Cerebral Cortex in Vitro. Journal of Physiology $(L), 375,169-194$. https://doi.org/10.1113/jphysiol.1986.sp016112

[21] Mednikova, Y.S., Karnup, S.V. and Loseva, E.V. (1998) Cholinergic Excitation of Dendrites in Neocortical Neurons. Neuroscience, 87, 783-796.

https://doi.org/10.1016/S0306-4522(98)00166-3

[22] Mednikova, Y.S., Kopytova, F.V. and Zhadin, M.N. (2010) Spontaneous Activity of Cortical Neurons in Vitro and Its Regulation by Acetylcholine. Neuroscience and Behavioral Physiology, 40, 986-992. https://doi.org/10.1007/s11055-010-9357-6

[23] Brown, D.A., Buckley, N.J., Caulfield, M.P., Duffy, S.M., Jones, S., Lamas, J.A., March, S.J., Robbins, J. and Selyanko, A.A. (1995) Coupling of Muscarinic Acetylcholine Receptors to Neural Ion Channels: Closure of $\mathrm{K}^{+}$Channels. In: Wess, J., Ed., Molecular Mechanisms of Muscarinic Acetylcholine Receptor Function, Springer Landes, New York, 165-182.

[24] Godfraind, J.M., Kawamura, H., Krnjević, K. and Pumain, R. (1971) Actions of Dinitrophenol and Some Other Metabolic Inhibitors on Cortical Neurons. Journal of Physiology (L), 215, 199-222. https://doi.org/10.1113/jphysiol.1971.sp009465

[25] Mednikova, Y.S. and Karnup, S.V. (1995) Functional Geometry of Amino Acid Sensitive Membrane of Layer V Neurons in the Guinea-Pig Neocortex in Vitro. Neuroscience, 69, 115-123. https://doi.org/10.1016/0306-4522(95)00189-P

[26] Sachs, L (1972) Statistische Auswertungsmethoden. Springer Verlag, Berlin, Heidelberg, New York. https://doi.org/10.1007/978-3-662-10037-0

[27] Pennartz, C.M.A., DeJeu, M.T.G., Geurtsen, A.M.S., Sluiter, A.A. and Hermes, M. (1998) Electrophysiological and Morphological Heterogeneity of Neurons in Slices of Rat Suprachiasmatic Nucleus. Journal of Physiology $(L)$, 506, 775-793. https://doi.org/10.1111/j.1469-7793.1998.775bv.x

[28] Mednikova, Y.S., Kopytova, F.V. and Zhadin, M.N. (2009) Levels of Spontaneous Activity and Spike Responses of Cortical Neurons to Local Administration of Excitatory Amino Acids to Their Dendrites and Bodies. Neuroscience and Behavioral Physiology, 39, 429-435. https://doi.org/10.1007/s11055-009-9159-x

[29] Williams, S.R. and Stuart, G.J. (2002) Dependence of EPSP Efficacy on Synapse Location in Neocortical Pyramidal Neurons. Science, 295, 1907-1910. https://doi.org/10.1126/science.1067903

[30] MacGregor, R.J. (1968) A Model for Responses to Activation by Axodendritic Synapses. Biophysical Journal, 8, 305-318. https://doi.org/10.1016/S0006-3495(68)86489-6

[31] Rall, W., Burke, R.E., Holmes, W.R., Jack, B., Redman, S.J. and Segev, I. (1992) Matching Dendritic Neuron Models to Experimental Data. Physiological Reviews, 72, S159-S186. https://doi.org/10.1152/physrev.1992.72.suppl 4.S159

[32] Aihara, H., Okada, Y. and Tamaki, N. (2001) The Effects of Cooling and Rewarming on the Neuronal Activity of Pyramidal Neurons in Guinea Pig Hippocampal Slices. Brain Research, 893, 36-45. https://doi.org/10.1016/S0006-8993(00)03285-6 
[33] Thompson, S.M., Masukawa, L.M. and Prince, D.A. (1985) Temperature Dependence of Intrinsic Membrane Properties and Synaptic Potentials in Hippocampal CA1 Neurons in Vitro. Journal of Neuroscience, 5, 817-824. https://doi.org/10.1523/JNEUROSCI.05-03-00817.1985

[34] Sarria, I., Ling, J. and Gu, J.G. (2012) Thermal Sensitivity of Voltage-Gated $\mathrm{Na}^{+}$ Channels and A-Type $\mathrm{K}^{+}$Channels Contributes to Somatosensory Neuron Excitability at Cooling temperatures. Journal of Neurochemistry, 122, 1145-1154. https://doi.org/10.1111/j.1471-4159.2012.07839.x

[35] Kang, J., Huguenard, J.R. and Prince, D.A. (1996) Development of BK Channels in Neocortical Pyramidal Neurons. Journal of Neurophysiology, 76, 188-198. https://doi.org/10.1152/jn.1996.76.1.188

[36] Kim, K.-R., Lee, S.Y., Yoon, S.H., Kim, Y., Jeong, H.-Yu., Lee, S., Suh, Y.H., Kung, J.-S., Cho, H., Lee, S.-H., Kim, M.-H. and Ho, W.-K. (2020) Kv4.1 a Key Ion Channel for Low Frequency Firing of Dentate Granule Cells, Is Crucial for Pattern Separation. Journal Neuroscience, 40, 2200-2214. https://doi.org/10.1523/JNEUROSCI.1541-19.2020

[37] Mokrushin, A.A., Pavlinova, L.I. and Borovikov, S.E. (2014) Influence of Cooling Rate on Activity of Ionotropic Glutamate Receptors in Brain Slices at Hypothermia. Journal of Thermal Biology, 44, 5-13. https://doi.org/10.1016/j.jtherbio.2014.05.005

[38] Volgushev, M., Kudryashov, I., Chistiakova, M., Niesmann, J. and Eysel, U.T. (2004) Probability of Transmitter Release at Neocortical Synapses at Different Temperatures. Journal of Neurophysiology, 92, 212-220. https://doi.org/10.1152/jn.01166.2003

[39] Adams, P.R., Brown, D.A. and Constanti, A. (1982) Pharmacological Inhibition of the M-Current. Journal of Physiology (L), 332, 223-262.

https://doi.org/10.1113/jphysiol.1982.sp014411

[40] Houser, C.R., Crawford, G.D., Salvaterra, P.M. and Vaughn, J.E. (1985) Immunocytochemical Localization of Choline Acetyltransferase in Rat Cerebral Cortex: A Study of Cholinergic Neurons and Synapses. Journal of Comparative Neurology, 234, 17-34. https://doi.org/10.1002/cne.902340103

[41] Dienel, G.A. (2017) The Metabolic Trinity, Glucose-Glycogen-Lactate, Links Astrocytes and Neurons in Brain Energetics, Signaling, Memory, and Gene Expression. Neuroscience Letters, 637, 18-25. https://doi.org/10.1016/j.neulet.2015.02.052

[42] Falkowska, A., Gutowska, I., Goschorska, M., Nowacki, P., Chlubek, D. and Baranowska-Bosiacka, I. (2015) Energy Metabolism of the Brain, Including the Cooperation Between Astrocytes and Neurons, Especially in the Context of Glycogen Metabolism. International Journal of Molecular Sciences, 16, 25959-25981.

https://doi.org/10.3390/ijms161125939 